\title{
María Eduarda Mirande, Alejandra Siles, Mariel Quintana, (Coords), Los nortes del Hispanismo: territorios, itinerarios y encrucijadas, Jujuy, Universidad, 2017, 289 pp.
}

\author{
Guadalupe Ficoseco \\ Facultad de Humanidades y Ciencias Sociales, Universidad Nacional de Jujuy, Argentina \\ guadaysf@gmail.com
}

Este volumen reúne los discursos inaugurales, las conferencias plenarias y semiplenarias y las exposiciones de panelistas del XI Congreso Argentino de Hispanistas que se llevó a cabo en San Salvador de Jujuy en mayo del año 2017.

Las palabras de apertura de las anfitrionas inician el volumen. Graciela Balestrino, presidenta de la AAH (período 2014-2017), destaca la trayectoria de los investigadores que fortalecieron e impulsaron el área disciplinar en distintas universidades del país, mientras que María Eduarda Mirande reflexiona sobre el lema de la onceava edición instando a repensar los objetos de estudios del hispanismo. Inspirada en la noción de hispanismo entendida como categoría lógico-espacial que contribuye a erigir visiones fragmentadas, inclusivas, plurales y creativas, la presidenta de la Comisión Local Organizadora advierte la urgente necesidad de incorporar formas de alteridad, desafiando lo canónico y lo instituido que atenta contra las diferencias.

El cuerpo de las actas, constituido por seis conferencias y siete ponencias, está signado por una esa diversidad, que permite delinear el mapa de algunos de los principales itinerarios del hispanismo y sus territorios dentro y fuera de Argentina.

Entre esos itinerarios, se destacan los estudios sobre oralidad y el Romancero. La trayectoria del género en América fue el tema desarrollado por el presidente de la AIH, Aurelio González (Colegio de México), quien en su conferencia "Unidad y multiplicidad en el Romancero en América" analiza los elementos de unidad formal, temática y estilística del género, atendiendo asimismo a la multiplicidad y diferencias en la expresión romancística arraigada y adaptada a las diferentes regiones. Revisa versiones recogidas de la tradición oral moderna y recorre los distintos temas que aparecen en los romanceros regionales. Da cuenta de la integración del Romancero a la comunidad hispanoamericana, demostrando su carácter patrimonial, supranacional e intangible.

Como panelista, González profundizó aspectos esenciales de la transmisión oral y su importancia. En su trabajo "Propositividad y Normatividad en la Oralidad" señala las diferencias entre la actitud de la colectividad y la de los transmisores que efectúan la codificación y descodificación textual adheridos a los valores de la comunidad. El autor distingue entre textos tradicionales y populares, clasificando a los primeros como "esencialmente propositivos" y a los segundos como "normativos". No obstante, concluye afirmando que la transmisión oral es un elemento de conservación de un patrimonio comunitario que se estructura según objetivos y valoraciones particulares.

Gloria Chicote (IdIHCS-CONICET-UNLP), en "Interferencias oralidad / escritura / ideología en los romanceros de los siglos XVI y XVII", examina las características del proceso que protagoniza el romance desde la oralidad hacia la escritura y su retorno a la transmisión oral (siglos XVI y XVII). Evalúa el impacto de la imprenta sobre sus modos de circulación, atendiendo a las orientaciones y usos ideológicos de que fue objeto, especialmente, por las élites dominantes. Advierte que la vitalidad del género oral, nunca entró en contradicción con la tecnología de la imprenta y señala que el cambio estructural en los circuitos orales implicó la fijación de mensajes, alentó la subjetividad e ideología de los poetas. Se distingue el rumbo bifurcado en la fijación escrita del romancero desde el siglo XVI: la elite cultural y el público ampliado. 
"Prácticas discursivas orales en la emergencia de las letras castellanas" de Leonardo Funes (UBA/ IIBICRIT-SECRIT-CONICET), analiza el proceso de la emergencia de las letras en la lengua romance castellana a fines del siglo XII y principios del XIII. Parte de una pregunta: ¿cómo nace la literatura? Su punto de partida es el análisis del cruce de las prácticas discursivas orales y escritas de la cultura manuscrita, que ejemplifica con el texto Auto de los Reyes Magos al que caracteriza como oralidad graficada y testimonio del período de transición entre dialecto y lengua literaria. Para resonder, postula el surgimiento de la literatura como un entrecruzamiento de tradiciones letradas y populares, que sitúa en el encuentro de actores culturales: juglares, trovadores, clérigos y letrados al salir en busca de un nuevo público mayormente iletrado.

El teatro del siglo de Oro fue otro de los temas centrales. La conferencia inaugural "Sobre los inadvertidos itinerarios de la investigación filológica en los territorios del hispanismo", a cargo de Melchora Romanos (Instituto de Filología y Literaturas Hispánicas "Dr. Amado Alonso"), ofrece "un caso testigo" de los complejos itinerarios de la investigación filológica al desentrañar las razones de las distintas interpretaciones críticas que otorgan la condición de "extraña rareza" a las comedias Don Juan de Castro: parte I (1604-1608) y parte II (1608) de Lope de Vega. Siguiendo un minucioso rastreo de sus fuentes demuestra que estos textos atípicos se sitúan en una encrucijada. Una, a mitad de camino entre el drama genealógico y la comedia novelesca inspirada en una fuente literaria francesa, el Oliveros, traducida en 1499. La otra, vinculada a la exaltación del linaje nobiliario de Juan de Castro.

En "El teatro histórico de Lope de Vega y la relativización de las taxonomías", Florencia Calvo (IFyLH “Dr. Amado Alonso" UBA-CONICET) retomando sus investigaciones previas sobre la taxonomía del teatro de tema histórico de Lope para centrar sus reflexiones en una nueva etapa de estudios donde pone en diálogo tres ejes: Arte Lope, la edición de la obra dramática de Lope de Vega por Menéndez Pelayo y los trabajos de Lope no dramaturgo. Finalmente propone el desafío de flexibilizar la frontera entre los subgéneros dramáticos y producción dramática y no dramática de Lope para encontrar el equilibrio entre la moda de la crítica y los proyectos más amplios de sistematización sin perder las características básicas de las obras.

Por su parte, Marcela Beatriz Sosa (CICUNSa-ICSOH) en "Bajo el Imperio de la melancolía: La retórica teatral de lo efímero en El Melancólico de Tirso de Molina", indaga en la recurrencia de la melancolía y la locura como problemáticas de la época barroca en varios personajes de textos dramáticos. Parte de la concepción del término melancolía en el siglo XVII, definiéndolo como la serie de conductas humanas que escapaban de la normalidad, para analizar cómo actúa esta melancolía en la comedia El Melancólico de Tirso Molina. Advierte que esta melancolía surge de una pena amorosa concreta y expone las formas de melancolía y las estrategias melancólicas presentes en el texto. Determina que esta melancolía es el resultado de una situación implosiva en la que se manifiesta la impotencia ante el imperio de las pasiones.

Graciela Balestrino (UNSa), bajo el titulo "Trampantojo y espacio doméstico en dos comedias de Calderón: Casa con dos puertas, mala es de guardar y su versión paródica, La puerta con dos casas”, se centra en una cuestión barroca: la dificultad para discernir lo ilusorio y engañoso de lo verdadero. Considera que la similitud es ocasión de error y recorre brevemente las formas de trampantojo - ilusión con que se engaña a alguien haciéndole ver lo que no es- desde lo pictórico y arquitectónico del engaño óptico hasta el trampantojo teatral, mediante espacios, tiempos y acciones. Hubo varios autores que hicieron uso de esta técnica y la autora se centra en Calderón como el más hábil. En principio define la alternancia espacial de los sucesos y los núcleos de intriga.

La novela hispanoamericana fue objeto de dos conferencias, una a cargo de José Manuel Camacho Delgado (Universidad de Sevilla) y la otra, de Aníbal Biglieri (Universidad de Kentucky). El sevillano presentó "Las formas complejas de la violencia en la narrativa colombiana: Del bogotazo a la narcoliteratura", donde reflexiona sobre el giro dado por la literatura colombiana desde ciertos tópicos pintorescos hacia formas de corrupción y violencia, trayectoria que funda un metagénero narrativo denominado "novela del narcotráfico" o "novela de la droga" y que, finalmente, por sus filiaciones con la novela picaresca recibe el nombre de "novela sicaresca”. Analiza tres textos claves: El Cristo de espaldas (1952) y Manuel Pacho (1962) y El día señalado 
(1963). Estas dan cuenta de cómo la violencia ha sido interpretada en la narrativa colombiana, nutrida de estigmas históricos, temas, estereotipos y patrones que reproducen las modalidades discursivas de la llamada narcoliteratura.

Aníbal Biglieri nos aproxima al Norte argentino con su trabajo "La Puna de Héctor Tizón: Regiones naturales, espacios y lugares", y encuadra su contribución en torno a dos "giros": el "giro espacial" y el "giro narrativo"; de esta forma traza una "cartografía literaria" de la Puna, unidad temática a los relatos de Tizón. Para examinar la relación entre lenguaje y realidad, literatura y geografía, ficción y realismo propone tres formas del espacio: el percibido, el concebido y el vivido, instancias desde las cuales analiza la singular experiencia de la Puna en la óptica del escritor jujeño.

Sobre la temática de conversos y su literatura se presentó la conferencia "Fantasmas entre nosotros": Inquisición, inquisidores y otros aparecidos en la literatura de conversos" de Ruth Fine (Universidad Hebrea de Jerusalén), quien propone evaluar el procesamiento de la memoria traumática de la inquisición y sus agentes en textos literarios de conversos, que posibilitan leer la herida, no como modo de recuperación de la experiencia sino con el fin de generar procesos simbólicos de reinterpretación del pasado. Fine distingue cuatro grupos: "La literatura de conversos", "La inquisición en la creación de los conversos ibéricos", "La escritura de los conversos itinerantes" y "Judíos nuevos y la memoria de la Inquisición”. La escritura de conversos permite establecer tres objetivos: por un lado, se ofrece como un acto de resistencia; por otro, obedece a un fin proselitista y de fortalecimiento del proceso de re-judaización de los conversos y, por último, opera como voluntad de recuperación de la memoria de su traumático pasado.

La poesía contemporánea española estuvo representada en los paneles del XI Congreso Argentino de Hispanistas por Laura Scarano (Universidad Nacional de Mar del Plata - CONICET), quien en "Mujer contra ciudad: La poesía urbana de Gloria Fuertes" reflexiona sobre la veta fuertemente política de esta escritora y su mirada de la ciudad desde su condición de mujer. Atiende al contexto de producción -veinte años después de la guerra civil- cuando Fuertes escribe los primeros poemarios y advierte en sus producciones el modo en que la guerra aflora como memoria de violencia y saqueo. Scarano hábilmente desentraña el principio constructivo de la obra de Gloria Fuertes, que alterna humor y gravedad y reflexiona sobre la forma en que su poesía construye un ethos testimonial a través de marginales urbanos de la ciudad de posguerra. Fuertes representa una nueva forma de compromiso en la poesía española.

La última conferencia de este libro de actas es de carácter teórico. Alfredo Saldaña (Universidad de Zaragoza) reflexiona "Sobre el estatuto literario contemporáneo", partiendo de consideraciones iniciales sobre el estudio histórico del objeto "literatura". Su propuesta -sólidamente fundada sobre la cita de diferentes estudiosos como Bloom, Althusser, Marx, Eagleton, Bourdieu, Habermas, Baudrillard-, muestra el agotamiento de un paradigma historicista de corte positivista y el extraordinario desarrollo de los estudios de teoría literaria, historia comparada de la literatura y teoría de la historia literaria que apuestan por un nuevo concepto de "historia literaria". Marcadamente crítico, ideológico y estético, coloca el estudio de la literatura sobre un escenario transcultural y supranacional inmerso en las nuevas coordenadas antropológicas del ciberespacio. Según el autor, esto es lo que hace posible la existencia de una literatura crítica y disidente, y advierte que la literatura y las disciplinas científicas que se ocupan de su estudio constituyen escenarios adecuados para la construcción de debate sobre temas como el posnacionalismo, la transculturalidad, negociación política, cultural e identitaria que rigen el incierto devenir de la posmodernidad.

Los trabajos reseñados dan cuenta de las variadas temáticas y los diversos enfoques abordados durante las conferencias y paneles del XI Congreso Argentino de Hispanistas celebrado en Jujuy. Estos trabajos son un aporte a los estudios del hispanismo y muestran la expansión de sus límites y la permeabilidad de sus bordes, muestras de que en el Norte argentino se vivió un encuentro de particulares características, marcado por la experiencia de la frontera, lugar de intercambio y de celebración comunitaria. 